\title{
ANALISA CITRA HIPERSPEKTRAL DAUN DARI TANAMAN KELAPA SAWIT YANG MENGALAMI KEKURANGAN AIR MENGGUNAKAN PROGRAM MATLAB
}

\author{
JR. Lessy Eka Putri ${ }^{1}$, Minarni ${ }^{1, *}$, Feri Candra ${ }^{2}, \operatorname{Herman}^{3}$ \\ ${ }^{1}$ Jurusan Fisika FMIPA, Universitas Riau \\ ${ }^{2}$ Jurusan Teknik Elektro FT, Universitas Riau \\ ${ }^{3}$ Jurusan Biologi FMIPA, Universitas Riau \\ *E-mail korespondensi: minarni@ unri.ac.id
}

\begin{abstract}
The hyperspectral imaging method has been widely and intensively used in agriculture to find out various problems that occur in plants. Image processing is very important step in an imaging method. This research aims to create Matlab based program to be used to analyze the leaf image of oil palm plants that has experienced water deficiency. Reflectance intensity values were extracted from the process. The hyperspectral imaging system consisted of a $650 \mathrm{~nm}$ diode laser, a spectrograph, monochrome CMOS camera, and Matlab image processing program. The samplesused were 8 month old Tenera variety of oil palm seedlings which were treated to simulate water deficiency in the form of variations in the volume of water, namely $0 \mathrm{~mL}$ (without watering), $1000 \mathrm{~mL}, 2000 \mathrm{~mL}$, and $3000 \mathrm{~mL}$ (normal), 3 duplicates for each volume. The samples were given water volume of $1000 \mathrm{~mL}$ and $2000 \mathrm{~mL}$ for every 7 days in 21 days, while the sampleswith $3000 \mathrm{~mL}$ of water were watered every day. Image recording was done on the 21 st day for detached leaves at the the bottom part.The results showed that the Matlab program was able to separate each row from 15 images, each of which had a pixel size of $1280 \times 1024$ and merge each of the same lines into 1024 images with a pixel size of $1280 \times 15$. The reflectance intensity values were then obtained. The results showed that higher levels of water deficiency in plants produce increasing reflectance intensity values.
\end{abstract}

Keywords: Hyperspectral imaging, Reflectance intensity, Matlab, Oil palm leaves, Water deficiency

\begin{abstract}
ABSTRAK
Metode pencitraan hiperspektralyang diinduksi laser semakin intensifdigunakan dalam bidang pertanian untuk mengetahui berbagai permasalahan yang terjadi pada tanaman. Pengolahan citra sangat penting dalam suatu metode pencitraan. Penelitian ini bertujuan untuk membuat program pengolahan citra berbasis Matlab yang digunakan untuk menganalisa citra hiperspektral daun dari tanaman kelapa sawit yang mengalami kekurangan air sehingga diperoleh nilai intensitas reflektansi.Sistem pencitraan hiperspektral yang digunakan terdiri dari laser dioda $650 \mathrm{~nm}$, spektrograf, kamera CMOS monokrom, dan program pengolahan citra Matlab.Sampel yang digunakan adalah bibit tanaman kelapa sawit varietas Tenera berumur 8 bulan yang diberi perlakuan untuk mensimulasi kekurangan air berupa variasi pemberian volume air $0 \mathrm{~mL}$ (tanpa penyiraman), $1000 \mathrm{~mL}, 2000 \mathrm{~mL}$, dan $3000 \mathrm{~mL}$ (normal). Sampel yang diberi volume air $1000 \mathrm{~mL}$ dan $2000 \mathrm{~mL}$ disiram setiap 7 hari sekali selama 21 hari, sedangkan sampel yang diberi volume air $3000 \mathrm{~mL}$ disiram setiap hari. Perekaman citra daun yang dipotong dari setiap bibit tanaman dilakukan pada hari ke-2lpada bagian pangkal daun. Hasil penelitian menunjukkan bahwa program Matlab yang telah dibuat dapat digunakan untuk memisahkan setiap baris dari 15 citra yang masing-masing memiliki ukuran piksel $1280 \times 1024$ dan menggabungkan setiap baris yang sama menjadi 1024 citra dengan ukuran piksel masing-masing $1280 \times 15$ sehingga diperoleh nilai intensitas reflektansi.Tingkat kekurangan air yang semakin tinggi pada tanaman menghasilkan nilai intensitas reflektansi yang semakin meningkat.
\end{abstract}

Kata kunci: Pencitraan hiperspektral, Intensitas reflektansi, Matlab, Daun kelapa sawit, Kekurangan air

Diterima 04-09-2019 | Disetujui 30-09-2019| Dipublikasi 31-30-2019 


\section{PENDAHULUAN}

Metode pencitraan hiperspektral menghasilkan citra dengan pita panjang gelombang yang sempit dan berdekatan dalam jumlah besar. Setiap piksel dalam citra hiperspektral mengandung spektrum dari posisi tertentu dimana hasil spektrum bertindak seperti sidik jari yang dapat digunakan untuk mengkarakterisasi suatu objek. Setiap citra yang direkam oleh kamera mewakili satu garis dalam bentuk citra yang dihasilkan dari metode ini. Citra yang dibuat garis per garis kemudian digabungkan sehingga membentuk kubus citra hiperspektral tiga dimensi atau yang biasa disebut hypercubes, yaitu data tiga dimensi yang terdiri dari dua dimensi untuk menggambarkan informasi spasial dan yang ketiga untuk informasi spektral [1,2].

Tanaman kelapa sawit merupakan salah satu tanaman yang membutuhkan air dalam jumlah yang banyak. Salah satu faktor utama tinggi rendahnya produksi kelapa sawit adalah ketersediaan air yang cukup untuk pertumbuhan dan perkembangan tanaman kelapa sawit. Kekurangan air pada tanaman kelapa sawit dapat menyebabkan penurunan produksi karena terhambatnya pembentukan bunga, meningkatnya jumlah bunga jantan, pembuahan terganggu, gugur buah muda, bentuk buah kecil, dan rendemen buah rendah [3].

Pendeteksian kekurangan air pada tanaman dapat dilakukan menggunakan metode pencitraan hiperspektral pada daun. Metode ini menggabungkan teknik pencitraan dan teknik spektroskopi yang dapat memberikan informasi spasial dan spektral dari suatu objek. Metode pencitraan spektroskopi ini memiliki rentang panjang gelombang yang lebih luas atau lebih banyak jumlah pita spektrum yang dipindai untuk setiap piksel. Informasi yang didapatkan berupa serangkaian nilai piksel atau intensitas reflektansi pada setiap spektrum panjang gelombang dalam bentuk citra [4].

Pengolahan citra merupakan proses mempersiapkan citra agar dapat dianalisa.
Proses tersebut perlu diperhatikan supaya informasi yang diperoleh dari citra tidak ada yang hilang atau rusak. Proses pengolahan citra bertujuan untuk mendapatkan kualitas citra yang lebih baik agar mudah diinterpretasi oleh manusia atau mesin sehingga informasi yang didapatkan dari citra lebih jelas [5].Pengolahan citra dapat menggunakan program yang dibuat sendiri maupun program yang telah tersedia. Program pengolahan citra hiperspektral telah banyak dibuat dan tersedia secara komersial, dengan harga relatifmahal.Program alternatif yang sederhana diperlukan untuk pengolahan data citra hiperspektral.

Pada penelitian ini, program pengolahan citra berbasis Matlab dibuat untuk mengolah data citra hiperspektral sehingga diperoleh nilai intensitas reflektansi terhadap panjang gelombang. Nilai intensitas reflektansi yang didapat digunakan untuk menganalisa kekurangan air yang terjadi pada tanaman kelapa sawit menggunakan metode pencitraan hiperspektral pada daun.

\section{METODE PENELITIAN}

Alat-alat yang digunakan dalam penelitian ini adalah laser dioda yang memiliki panjang gelombang $650 \mathrm{~nm}$, spektrograf ImSpector V10, kamera CMOS monokrom, catu daya laser dioda, tempat sampel, meja optik, rel, dan laptop. Sistem pencitraan hiperspektral dilingkupi kotak hitam akrilik yang berfungsi untuk mengisolasi sistem dari cahaya luar. Skema sistem pencitraan hiperspektral ditunjukkanpada Gambar 1. Sampel yang digunakan dalam penelitian ini adalah bibit tanaman kelapa sawit varietas Tenera yang berumur 8 bulan.

Sampel diberi perlakuan berupa variasi tingkat kekurangan air. Variasi volume air yang diberikan sebesar $0 \mathrm{~mL}$ (tanpa penyiraman), $1000 \mathrm{~mL}, 2000 \mathrm{~mL}$, dan 3000 $\mathrm{mL}$ (normal).Penyiraman dilakukan setiap 7hari sekali untuk sampel yang mendapatkan perlakuan $1000 \mathrm{~mL}$ dan $2000 \mathrm{~mL}$ sedangkan sampel yang mendapatkan perlakuan $3000 \mathrm{~mL}$ 
disiram setiap hari.Setiap variasi volume terdiri dari tiga bibit tanaman kelapa sawit sehingga sampel berjumlah 12. Semua bibit diberi perlakuan yang sama selama tiga minggusetelah dipindahkan ke polibag. Perekaman citra dilakukan pada hari ke-21.

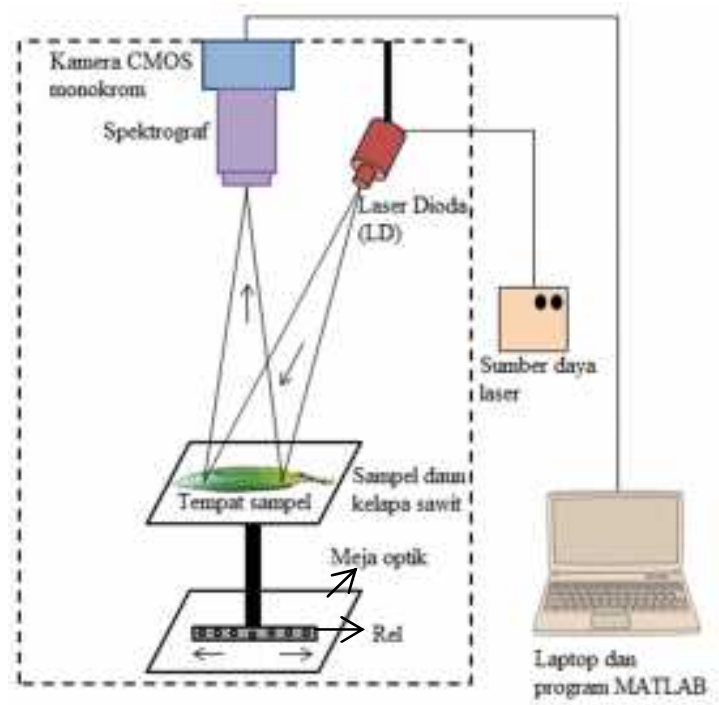

Gambar 1. Skema sistem pencitraan Hiperspektral.

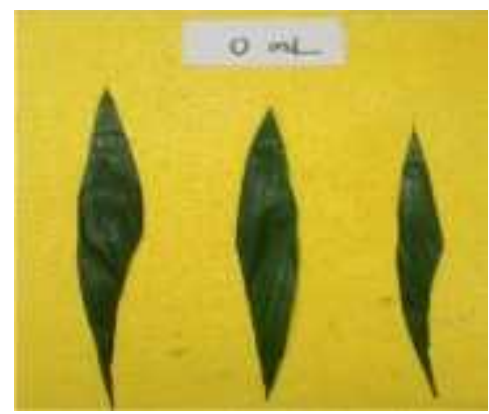

Gambar 2. Contoh sampel daun $0 \mathrm{~mL}$ (tanpa penyiraman).

Gambar 2 adalah contoh sampel daun tanpa penyiraman $0 \mathrm{~mL}$. Sampel ini merupakan daun kedua dari setiap bibit yang dipotong dan dibersihkan setelah hari ke 21. Sebelum citra diambil, pengukuran panjang dan lebar daundilakukan. Panjang daun yang diamati sebelum perlakuan pada volume air $0 \mathrm{~mL}$, $1000 \mathrm{~mL}, 2000 \mathrm{~mL}$, dan $3000 \mathrm{~mL}$ masingmasing adalah $44 \mathrm{~cm}, 36 \mathrm{~cm}, 39 \mathrm{~cm}$, dan 40 $\mathrm{cm}$. Setelah mengalami perlakuan, panjang masing-masing adalah $46 \mathrm{~cm}, 36,6 \mathrm{~cm}, 41,3$ $\mathrm{cm}$, dan 40,2 cm. Lebar daun masing-masing sebelum perlakuan adalah $4,2 \mathrm{~cm}, 5,4 \mathrm{~cm}, 6,1$ $\mathrm{cm}$, dan 7,1 cm dan sesudah perlakuan selama 21 hari adalah 4,5 cm, 5,6 cm, 6,4 cm, dan 7,4 $\mathrm{cm}$. Pencitraan dilakukan pada bagian pangkal daun.

Kalibrasi kamera perlu dilakukan dalam penelitian ini. Kalibrasi yang dilakukan adalah kalibrasi posisi piksel ke panjang gelombang. Kalibrasi tersebut bertujuan untuk mengetahui panjang gelombang untuk setiap piksel. Kalibrasi ini menggunakan sumber cahayaLD merah $650 \mathrm{~nm}$ dan LD ungu $405 \mathrm{~nm}$ serta sistem pencitraan hiperspektral. LD merah 650 $\mathrm{nm}$ dan LD ungu $405 \mathrm{~nm}$ diarahkan ke spektrograf secara bergantian untuk menghasilkan citra seperti yang terlihat pada Gambar 3.

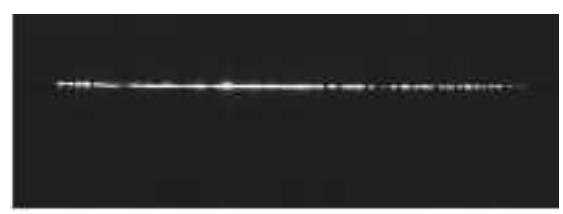

(a) Citra untuk LD merah $650 \mathrm{~nm}$

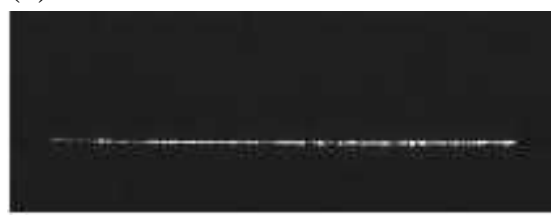

(b) Citra untuk LD ungu $405 \mathrm{~nm}$

Gambar 3. Citra kalibrasi.

Program Matlab digunakan untuk menentukan posisi baris pada intensitas maksimum dari citra yang diperolehyang dapat dilihat dari nilai matriks masing-masing citra. Intensitas maksimum dihasilkan apabila matriks menunjukkan nilai sebesar 255. Proses tersebut menghasilkan bahwa LD merah 650 $\mathrm{nm}$ memiliki intensitas maksimum pada baris ke-388, sementara LD ungu $405 \mathrm{~nm}$ memiliki intensitas maksimum pada baris ke-671.

Setelah proses kalibrasi dilakukan, daun diletakkan pada tempat sampel seperti pada Gambar 1. Daun tersebut disinari dengan laser dioda yang berkasnya telah diperbesar mengunakan lensa yang terletak di depan LD sehingga mengenai daun pada bagian pangkal. Bagian pangkal mempunyai luaspermukaan yang lebih besar. Sumber cahaya diarahkan ke sampel yang digerakkan menggunakan rel. 
Cahaya yang mengenai permukaan daun akan menghasilkan proses reflektansi atau pemantulan. Cahaya yang dipantulkan dari daun menujuke dalam spektrograf melalui celah, kemudian cahayamasuk ke kamera CMOS monokrom yang menangkap sinyal berupa cahaya dan menghasilkan keluaran dalam bentuk citra yang tampil pada layar laptop. Kamera CMOS monokrom yang digunakan dalam penelitian ini memiliki resolusi $1280 \times 1024$ piksel. Citra yang diambil untuk setiap 1 helai bagian pangkal daun sebanyak 15 citra yang dihasilkan dengan menggeser atau menggerakkan tempat sampel sejauh $2 \mathrm{~mm}$ untuk setiap 1 citra. Metode ini disebut metode scanninguntuk memperoleh deretan citra garis.Hasil rekaman citra daun tersebut disimpan dalam bentuk format BMP yang kemudian diolah menggunakan program Matlab untuk mendapatkan nilai intensitas reflektansi darisetiap piksel citra.

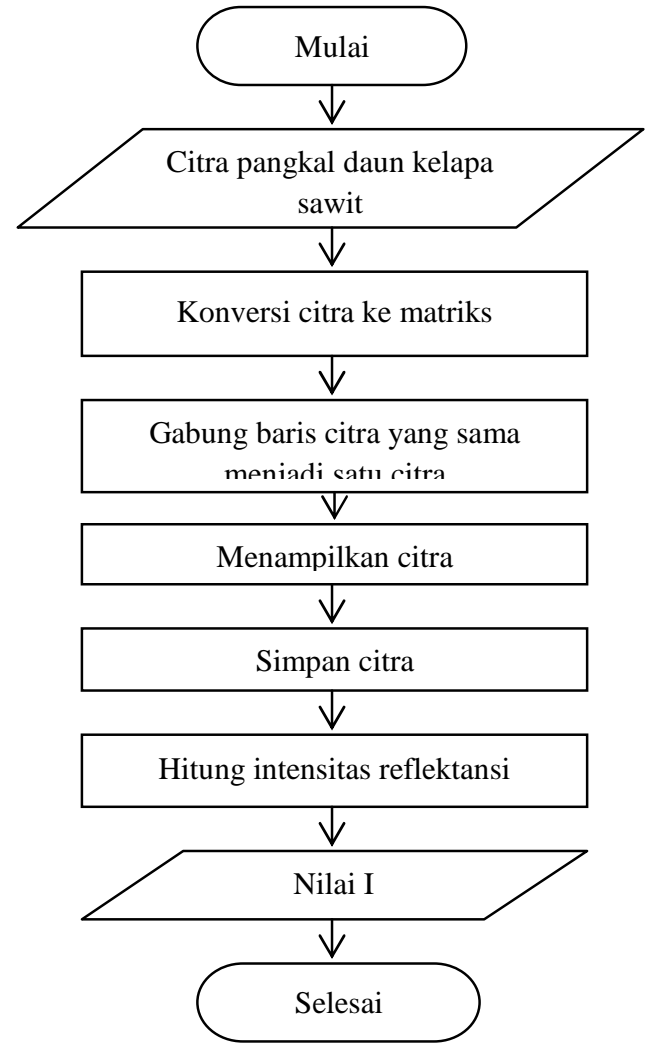

Gambar 4.Diagram alir program Matlab.

Diagram alir program Matlab diperlihatkan pada Gambar 4.Tahapan dari diagram alir tersebut adalah input citra pangkal daun kelapa sawit, lalu konversi citra ke matriks, kemudian memisahkan setiap baris dari 15 buah citra pangkal daun yang telah didapatkan dimana masing-masing citra memiliki ukuran piksel $1280 \times 1024$ dan menggabungkan setiap baris yang sama menjadi 1024 citra dengan ukuran piksel masing-masing $1280 \times 15$ sehingga diperoleh nilai intensitas reflektansi.

\section{HASIL DAN PEMBAHASAN}

Program Matlab untuk pengolahan data citra hiperspektral sehingga diperoleh nilai intensitas reflektansi telah berhasil dibuat. Citra hiperspektral daun yang diperoleh pada penelitian ini ditunjukkan oleh Gambar 5.

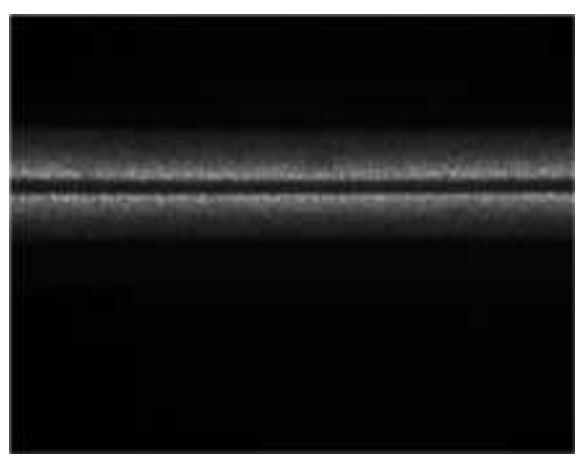

Gambar 5. Citra hiperspektral pangkal daun 0 $\mathrm{mL}$ pada hari ke-21

Citra yang diambil untuk setiap 1 sampel daun sebanyak 15 citra dengan ukuran piksel $1280 \times 1024$ untuk masing-masing citra. Pengolahan citra daun dilakukan dengan menggunakan Graphical User Interface (GUI) di Matlab untuk memisahkan setiap baris dari masing-masing 15 citra. Setiap baris yang sama digabungkan menjadi 1 citra baru yang memiliki ukuran piksel 1280× 15.Proses pengolahan tersebut akan menghasilkan 1024 citra baru.Gambar 6 menunjukkan tampilan menu utama program Matlab yang telah dibuat dengan nama Sistem Bantu. Bagian a berfungsi untuk memasukkan nilai baris ke berapa yang ingin digabungkan, bagian $b$ atau tombol Start memproses citra yang akan digabungkan sehingga akan terlihat hasil citra pada bagian d. Bagian c atau tombol Save berfungsi untuk menyimpan citra baru dalam format BMP dengan ukuran piksel $1280 \times 15$. 


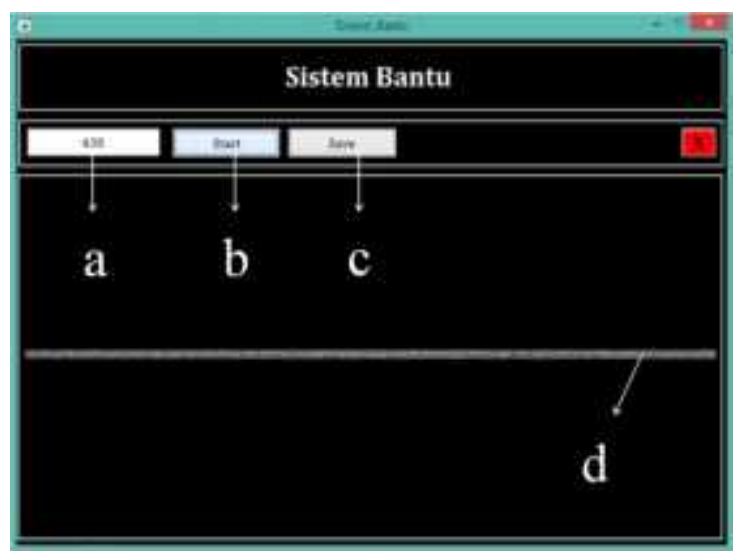

Gambar 6.Tampilan menu utama program Matlab.

Citra baru dihasilkan sebanyak 1024 citra untuk setiap 1 sampel daun. Nilai intensitas reflektansi masing-masing citra ditentukan dari nilai piksel citranya. Nilai-nilai tersebut dirataratakan berdasarkan jumlah piksel. Penentuan nilai intensitas reflektansi tersebut dilakukan dengan progam Matlab. Nilai intensitas reflektansi yang telah didapatkan akan menghasilkan grafik yang menunjukkan hubungan intensitas reflektansi terhadap variasi pemberian volume air dari daun tanaman kelapa sawit pada penelitian ini.

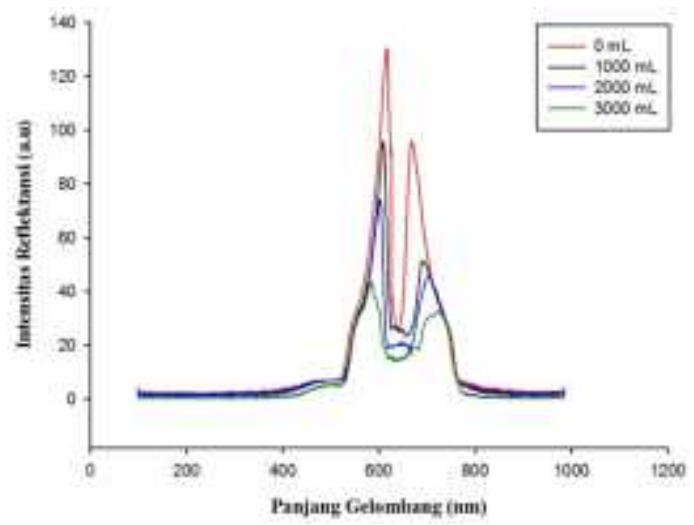

Gambar 7. Hubungan antara intensitas reflektansi terhadap panjang gelombang terhadap variasi pemberian volume air pada hari ke-21.

Grafik hubungan antara nilai intensitas reflektansi rata-rata terhadap variasi pemberian volume air pada tanaman kelapa sawit ditunjukkan oleh Gambar 7. Grafik tersebut diperoleh dari nilai intensitas reflektansi yang berasal dari citra pangkal daun kelapa sawit.
Tanaman yang tidak mendapatkan kebutuhan air yang cukup, yaitu tanaman yang tidak disiram $(0 \mathrm{~mL})$ dan tanaman yang disiram (1000 mL dan $2000 \mathrm{~mL}$ ) memiliki nilai intensitas reflektansi yang lebih tinggi dibandingkan dengan tanaman yang mendapatkan kebutuhan air yang cukup (3000 $\mathrm{mL}$ ). Tanaman yang tidak disiram dan yang diberi $1000 \mathrm{~mL}$, dan $2000 \mathrm{~mL}$ volume air menyerap cahaya lebih sedikit dan memantulkan cahaya lebih banyak dibandingkan tanaman yang disiram normal sebanyak $3000 \mathrm{~mL}$. Hal ini menunjukkan bahwa semakin tinggi intensitas reflektansi yang dihasilkan mengidentifikasi bahwa kandungan klorofil pada tanaman tersebut semakin rendah dan sebaliknya [6].

Tanaman yang mengalami cekaman menghasilkan pemantulan yang semakin tinggi karena berkurangnya penyerapan cahaya oleh tanaman.Kandungan klorofil pada daun tanaman mempengaruhi intensitas reflektansi. Semakin tinggi cahaya yang dipantulkan oleh suatu tanaman menunjukkan bahwa kandungan klorofil tanaman tersebut rendah sehingga cahaya laser dioda $650 \mathrm{~nm}$ yang diserap juga akan semakin sedikit dan menghasilkan intensitas reflektansi yang lebih tinggi pada tanaman yang mengalami kekurangan air [7].

\section{KESIMPULAN}

Berdasarkan hasil penelitian dan analisa grafik hubungan intensitas reflektansi terhadap variasi pemberian volume air, maka dapat ditarik beberapa kesimpulan, yaituprogram Matlab yang telah dibuat dapat digunakan untuk mengolah data citra hiperspektral dengan cara memisahkan setiap baris dari 15 buah citra yang masing-masing memiliki ukuran piksel $1280 \times 1024$ dan menggabungkkan setiap baris yang sama menjadi 1024 citra dengan ukuran piksel masing-masing $1280 \times 15$ sehingga diperoleh nilai intensitas reflektansi.Pemberian volume air yang kurang darivolume air normal menghasilkan nilai intensitas reflektansi yang lebihtinggi atau tingkat kekurangan air yang semakin tinggi pada tanaman kelapa sawit 
menyebabkan cahaya yang diserap semakin sedikit dan cahaya yang dipantulkan atau intensitas reflektansi semakin meningkat.

\section{UCAPAN TERIMA KASIH}

Penulis mengucapkan terima kasih kepada BPDPKS yang telah membiayai sebagian penelitian ini melalui penggunaan spektrometer Specim V10 dan sistem pencitraan hiperspektral melalui grant riset sawit PRJ no 33. 2018

\section{DAFTAR PUSTAKA}

1. Elrahman, A. A., Pand-Chhetri, R., and G. Vallad. (2011). Design and Development of A Multi-Purpose LowCost Hyperspectral Imaging System. Remote Sensing, 3: 570-586.

2. Sun, D. W. (2010). Hyperspectral Imaging for Food Quality Analysis and Control. London: Academic Press.

3. Hidayat, T.C., Harahap, I.Y.,
Pangaribuan, Y., Rahutomo, S., Harsanto, W.A., dan W.R. Fauzi. (2013). Air dan Kelapa Sawit. Medan: Pusat Penelitian Kelapa Sawit.

4. Sankaran, S., A. Mishra, A., Ehsani, R., and C. Davis. (2010). A Review of Advanced Techniques for Detecting Plant Diseases. Computers and Electronics inAgriculture, 72: 1-13.

5. Gonzalez, R. C., Woods, R. E., and S. L. Eddins. (2009). Digital Image Processing Using MATLAB. India: Pearson Education.

6. Chong, Y. M., Balasundram, S. V., and A. H. M. Hanif. (2017). Detecting and Monitoring Plant Nutrient Stress Using Remote Sensing Approaches: A Review. Asian Journal of Plant Sciences, 16: 1-8.

7. Kim, Y., Glenn, D. M., Park, J., Ngugi, H. K., and B. L. Lehman. (2011). Hyperspectral Image Analysis for Water Stress Detection of Apple Trees. Computers and Electronics in Agriculture, 77: 155-160. 